\title{
Analisis Brand Activation Hellobeauty dalam Membangun Loyalitas Konsumen
}

\author{
Yuli Yantimas, Diah Ayu Candraningrum \\ yuliyantimas.915150068@stu.untar.ac.id,diahc@fikom.untar.ac.id
}

Fakultas Ilmu Komunikasi Universitas Tarumanagara

\begin{abstract}
HelloBeauty is a start-up company that is developing in the number one beauty services business in Indonesia. HelloBeauty is based online. In developing its business HelloBeauty conducts promotions online and offline. HelloBeauty collaborates with a number of beauty artists around 10,000. Dennish Tjandra who started his business was inspired by his wife who had difficulty in finding a makeup artist. That makes Dennish try to make a program that makes it easy for women in Indonesia to find beauty artists that are suitable for their location, price, and suitability of their makeup. This study uses qualitative research methods that use interview techniques. Some offline and online events held are Giovanni's makeup event, Bubah Alfian, and Makeup Artist Gathering. Offline events are done by giving various giveaway. Some ways to promote HelloBeauty is to do brand activation. The two strategies chosen were social media activation and marketing event activation. Promotional activities through social media are run by HelloBeauty from the very beginning. 40 events from 2017 to mid 2019 have been held. Dennish believes that with this offline event, HelloBeauty will be very helpful in communicating directly with beauty artists and HelloBeauty consumers. The results of this study are loyalty built from HelloBeauty consumers.
\end{abstract}

Keywords: HelloBeauty, Brand Activation, Instagram, Event.

\begin{abstract}
Abstrak
HelloBeauty merupakan perusahaan start-up yang berkembang dalam usaha bisnis jasa kecantikan nomor satu di Indonesia. HelloBeauty yang berbasis online. Dalam mengembangkan bisnisnya HelloBeauty melakukan promosi secara online maupun offline. HelloBeauty menggandeng sejumlah beauty artist sekitar kurang lebih 10.000. Dennish Tjandra yang memulai bisnisnya terinspirasi dari istrinya yang kesulitan dalam mencari makeup artist. Hal itu yang membuat Dennish mencoba untuk membuat sebuah program yang memudahkan perempuan di Indonesia untuk mencari beauty artist yang sesuai dengan lokasi, harga, dan kecocokan makeupnya. Penelitian ini menggunakan metode penelitian kualitatif yang menggunakan teknik wawancara. Beberapa event offline maupun online yang diselenggarakan adalah event makeup dengan Giovanni, Bubah Alfian, dan Gathering Makeup Artist. Untuk event offlinenya dilakukan dengan melakukan berbagai giveaway. Beberapa cara promosi yang dilakukan HelloBeauty adalah dengan melakukan brand activation. Dua strategi yang dipilih adalah social media activation dan marketing event activation. Kegiatan promosi melalui media sosial dijalankan oleh HelloBeauty dari awal mula berdiri. Event yang sudah diselenggarakan sebanyak 40 event mulai dari tahun 2017 sampai pertengahan 2019. Dennish meyakini bahwa dengan adanya event offline ini, akan sangat membantu HelloBeauty dalam berkomunikasi secara langsung dengan beauty artist maupun konsumen HelloBeauty. Hasil dari penelitian ini adalah loyalitas yang terbangun dari konsumen HelloBeauty.
\end{abstract}

Kata Kunci: HelloBeauty, Brand Activation, Instagram, Event. 


\section{Pendahuluan}

Dengan kemajuan internet maka muncullah e-marketplace yang merupakan pasar virtual dimana penjual dan pembeli bertemu dan melakukan berbagai jenis transaksi. Di sini orang melakukan proses transaksi dengan pertukaran barang maupun jasa untuk menghasilkan uang. Transaksi dalam dunia internet diartikan sebagai e-commerce. Terdapat berbagai macam jenis transaksi yang dapat dilakukan dengan media internet, seperti: transaksi berupa blog, transaksi di forum, media sosial, toko online dan e-marketplace menurut Shabur, Heru, dan Riadi (2015).

E-Marketplace sebagai tempat bertemunya penjual dan pembeli secara online mempunyai beberapa manfaat yaitu; memperluas jaringan dan meningkatkan penjualan khususnya bagi usaha kecil dan usaha mandiri yang bermodal menengah ke bawah ataupun wirausaha baru yang sedang merintis bisnis atau usahanya, $e$ marketplace sangat cocok untuk sarana penjualan mengenalkan produk bahkan menjaga komunikasi dan memperbanyak relasi, karena tidak membutuhkan biaya yang besar seperti pasar secara fisik, e-marketplace tidak terbatas oleh waktu dan kondisi geografis bisa diakses dimana saja dan kapan saja sehingga sangat bagus untuk peningkatan penjulan dan pengenalan produk di lingkup yang lebih luas menurut ( Frans, 2012).

Ketua Umum Kamar Dagang dan Industri Indonesia (KADIN), Rosan $\mathrm{P}$ Roeslani, mengungkapkan jika keberadaan marketplace seperti Bukalapak dan Tokopedia menjadi penting di tengah perkembangan teknologi saat ini. Sebab, kehadirannya mendongkrak sektor Usaha Mikro Kecil dan Menengah (UMKM). (https://www.liputan6.com/bisnis/read/3905013/kadin-akui-marketplace-berikanakses-pasar-besar-buat-ukm diakses pada tanggal 24 Februari 2019 pada pukul 12.50)

CEO HelloBeauty melihat bahwa adanya peluang dalam bisnis ini. HelloBeauty juga sering mengadakan kegiatan event yang dihadiri oleh beauty artist membuat penulis mengetahui bahwa HelloBeauty berusaha mewadahi makeup artist sebagai upaya dalam menanamkan salah satu strategi brand activation. HelloBeauty menyelenggarakan promosi yang menarik melalui berbagai event dengan tujuan untuk membangun brand activation.

Definisi dari event adalah suatu kegiatan yang diselenggarakan untuk memperingati beberapa hal penting sepanjang hidup manusia, baik secara individu atau kelompok yang terikat secara adat,budaya,tradisi, dan agama yang diselenggarakan untuk tujuan tertentu dan melibatkan lingkungan masyarakat pada waktu tertentu (Ani Noor, 2009).

\section{Metode Penelitian}

Penelitian ini menggunakan metode penelitian kualitatif. Metode penelitian ini dilakukan dengan pertimbangan yang sesuai dengan judul yaitu Analisis Brand Activation HelloBeauty Dalam Membangun Loyalitas Konsumen. Menurut Bogdan dan Taylor (1992), penelitian kualitatif merupakan sebuah prosedur penelitian yang menghasilkan data deskriptif berupa ucapan, tulisan, perilaku orang yang diamati (Sujarweni, 2014).

Metode penelitian yang digunakan oleh peneliti pada penelitian ini adalah metode studi kasus. Emzir mengemukakan bahwa, penelitian studi kasus ini merupakan sebuah penelitian kualitatif yang berusaha menemukan makna, 
menyelidiki proses dan memperoleh pengertian dan pemahaman yang mendalam dari individu, kelompok atau situasi (Emzir, 2016). Peneliti melihat adanya keunikan yang terlihat nyata dari HelloBeauty. Penulis memilih metode studi kasus, karena strategi brand activation yang dilakukan oleh HelloBeauty melalui berbagai event offline maupun online merupakan sebuah kasus yang menarik untuk diteliti. Penelitian ini bertujuan untuk menganalisa dan mengkaji secara mendalam mengenai strategi yang dilakukan oleh HelloBeauty dalam membangun loyalitas konsumen melalui strategi brand activation.

Dalam sebuah penelitian haruslah terdiri dari subyek dan obyek. Obyek penelitian adalah orang, tempat, atau benda yang diamati dalam pembubutan sebagai sasaran menurut (Moleong,2010). Obyek dalam penelitian ini adalah strategi brand activation melalui event. Subyek penelitian dalam penelitian ini adalah HelloBeauty.

Teknik pengumpulan data yang dilakukan oleh penulis melalui beberapa cara yaitu; melakukan wawancara dengan beberapa konsumen, makeup artist, CEO HelloBeauty. Pihak-pihak tersebut merupakan kunci utama dalam mencapai tujuan dari penelitian ini. melakukan observasi non-partisipan melalui pengamatan yang penulis lihat dan dengar melalui berbagai acara offline maupun online yang sudah dilaksanakan oleh HelloBeauty. Peneliti juga mendengarkan beberapa pendapat dari orang - orang yang mengikuti acara tersebut, dan beberapa masyarakat yang sudah menggunakan HelloBeauty. memanfaatkan buku dan teori yang telah dipelajari dan dibaca yang berkaitan dalam bidang Ilmu Komunikasi, masalah penelitian dan metode penelitian sebagai sumber data dan landasan teori yang mendukung penelitian ini. Penelusuran data online melalui internet untuk mencari dan mendapatkan data-data yang diperlukan dalam penelitian.

Dalam penelitian ini, penulis menggunakan triangulasi dengan sumber data. Menurut Patton (1987) (dalam Moleong, 2008 : 330), triangulasi dengan sumber berarti membandingkan dan mengecek baik derajat kepercayaan suatu informasi yang diperoleh melalui waktu dan alat yang berbeda dalam penelitian kualitatif. Penulis mencocokan kembali hasil pengamatan dan hasil wawancara.

\section{Hasil Temuan dan Diskusi}

HelloBeauty merupakan sebuah perusahaan marketplace yang menghubungkan makeup artist (MUA) dan klien. Terinspirasi oleh istrinya yang sudah sekitar 8 tahun bersama. Dennish menjelaskan bahwa istrinya sangat mendukungnya dalam mendirikan HelloBeauty. Bermula dari tidak memiliki pekerjaan yang tetap, perekonomian yang kurang baik, Dennish mendirikan HelloBeauty. CEO HelloBeauty mendirikan bisnis kecantikan yang berbasis online ini. Didorong oleh keinginan untuk memecahkan masalah terkait kecantikan. HelloBeauty mempunyai nama dan lambang logo yang menarik dengan warna pink dan lukisan pada hurufnya. Nama HelloBeauty diartikan agar dalam mencari Makeup atau jasa kecantikan semudah mengatakan kata Hello. Dennish menjelaskan bahwa ia ingin namanya mudah diingat.

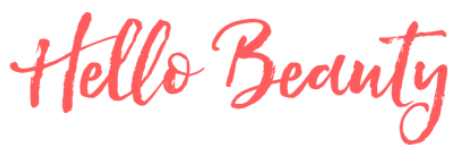

Gambar 4.1 Logo HelloBeauty 
Beberapa pelayanan yang disediakan oleh HelloBeauty adalah jasa makeup dan hairdo, wedding makeup, pre-wedding makeup, lamaran makeup, ulang tahun makeup, pesta makeup, photoshoot makeup, komersial makeup, dan makeup untuk sehari-hari. Saat ini HelloBeauty sudah merambat dalam dunia kecantikan yang baru seperti eyelash extention, nail art, sulam alis. HelloBeauty berperan secara aktif dalam dunia kecantikan. HelloBeauty menyediakan jasa ini bukan hanya di Jakarta, namun meliputi beberapa kota besar yang ada di Indonesia.

Untuk menggandeng makeup artist, Dennish mengungkapkan bahwa pihaknya melakukan berbagai pencarian melalui Instagram yang digunakan sebagai wadah MUA dalam menampilkan portofolionya. HelloBeauty juga membuka pendaftaran di situs web bagi MUA yang ingin bergabung. Dennish menjelaskan bahwa saat ini belum ada marketplace serupa HelloBeauty di Indonesia. Layanan lain yang juga menyediakan jasa kecantikan adalah GO-GLAM dari Gojek, dan Vanitee dari Singapura.

Walaupun masih dianggap sebagai perusahaan start-up namun tidak membuat HelloBeauty menjadi tidak mampu bersaing dengan perusahaan besar lainnya. Hellobeauty telah berhasil meraih gelar "Best Of The Best The NextDev Talent Scouting 2018”.

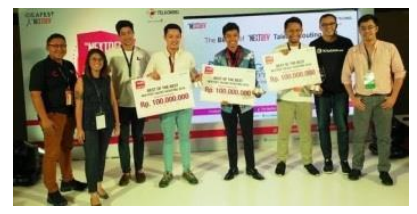

Gambar 4.3 HelloBeauty memenangkan The NextDev

Sumber : Dokumentasi dari Informan

HelloBeauty juga berhasil meraih gelar pertama nominasi Global start-up di Beijing dalam acara "She Loves Tech" tahun 2018.

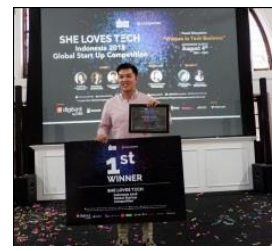

Gambar 4.4 HelloBeauty memenangkan She Love Tech

Sumber : Dokumentasi dari Informan

\section{Brand activation}

Dalam penelitian ini penulis mewawancara Dennish Tjandra selaku CEO HelloBeauty, Lanny Wijaya dan Florence sebagai makeup artist, dan Nike Apriyani dan Tjong Stephany Hendarmin sebagai pelanggan HelloBeauty. Dennish melakukan brand activation melalui dua cara yaitu dengan social media activation dan marketing event activation. Dalam social media activation, dennish menggunakan Instagram dan web milik HelloBeauty. Social media activation merupakan sebuah strategi pemasaran merek yang digunakan melalui media sosial seperti Instagram, Google Ads, dan Web. Hellobeauty yang mengawali promosi pertamanya melalui web, dan dilanjutkan melalui instagram, hingga sekarang HelloBeauty sudah memiliki aplikasi sendiri. Dennish menjelaskan bahwa permasalahan awal yang dimiliki oleh MUA itu sendiri adalah mereka belum memahami tentang bisnis. Dengan hanya bermodalkan skill, mereka membuka bisnisnya sendiri yang belum 
Yuli Yantimas, Diah Ayu Candraningrum: Analisis Brand Activation Hellobeauty dalam Membangun Loyalitas Konsumen

tertata rapih. Keuntungan yang dijelaskan oleh Dennish mengenai brand activation adalah untuk membuat masyarakat sadar akan kehadiran HelloBeauty dan juga untuk menjalin hubungan dengan konsumen melalui acara-acara yang diadakan secara offline oleh Hellobeauty.

\section{Marketing Event Activation}

Event merupakan sebuah kegiatan yang diselenggarakan untuk memperingati beberapa hal penting. Event diadakan untuk mendatangkan sejumlah pengunjung yang mencapai target ataupun melebihi target yang diharapkan atau ditetapkan. Karena jumlah pengunjung yang sesuai atau melebihi target adalah salah satu kesuksesan sebuah event (Ani Noor, 2009).

Beberapa event yang diadakan oleh HelloBeauty dan merupakan salah satu event yang belum pernah dilakukan di tempat lain adalah MUA Gathering. Dalam event ini, HelloBeauty bekerjasama dengan social cosmetics sebagai pengisi acara. MUA gathering ini diadakan pada hari kamis 16 Agustus 2018 yang bertempat di POP UP station Sarinah Mall, acara ini dihadiri oleh 30 orang MUA HelloBeauty. Didalam acara ini, social cosmetics memeriahkan acara dengan melakukan games berkelompok untuk menghasilkan makeup 10 menit dan bagi pemenang akan mendapatkan doorprize dari social cosmetics. Dennish menjelaskan bahwa beliau melihat bahwa untuk dapat maju bersama harus dimulai dari lingkungan dalam, sehingga beliau mengadakan acara ini.

Event kedua yang diadakan oleh HelloBeauty bersama Giovanni Nathalie dengan tema wedding makeup dan business class. Berbeda dengan makeup class sebelumnya, pada acara kali ini Giovanni Nathalie menjelaskan beberapa cara yang harus dipahami oleh beauty artist seperti pricing yaitu bagaimana cara menghitung harga makeup supaya beauty artist tidak merugi. Selanjutnya Giovanni menjelaskan bahwa makeup artist harus mempunyai attittude dalam pekerjaan. Hal ini juga sejalan dengan pendapat salah satu konsumen HelloBeauty yang menjelaskan bahwa HelloBeauty belum bisa mengetahui karakter beauty artistnya. Dalam hal ini katakan bahwa Nike pernah menemui salah satu beauty artist yang datang kerumah namun memiliki beberapa personality.

Mahdalena (2016) menjelaskan ada 5 atribut untuk meningkatkan pengalaman event yaitu : Involvement sebuah keterlibatan emosional masyarakat dengan merek, event, dan pengalaman. HelloBeauty melakukan teknik ini karena menurutnya dengan adanya kegiatan offline yang melibatkan member HelloBeauty untuk mengikuti acara yang diselenggarakan akan membangun emosional membernya untuk terus loyal terhadap produknya.

Interaction yang merupakan salah satu kegiatan yang dilakukan dengan brand ambassadors dengan pertunjukan yang disediakan, dengan karyawan, dengan peserta. HelloBeauty juga menerapkan konsep ini karena menurutnya berinteraksi secara langsung dapat membangun komunikasi. Interaksi juga merupakan salah satu faktor sebuah acara berhasil. Melalui interaksi, peserta akan merasa mereka beruntung dapat mengikuti acara tersebut.

Setelah berinteraksi membuat konsumen merasa nyaman, selanjutnya adalah Intensity yang merupakan sebuah kegiatan yang mudah diingat, dan memiliki pengaruh yang cukup tinggi. HelloBeauty dalam membuat eventnya selalu berbeda dengan sebelumnya, memberikan pengalaman yang berbeda dengan beberapa kegiatan yang ada didalamnya. Dengan membuat kegiatan yang mudah diingat, 
peserta akan selalu dapat mengingat dan bahkan menceritakan acara tersebut kepada rekan, dan keluarga tanpa perlu dibayar.

Individuality yang artinya memiliki kepribadian, unik, ada kesempatan satu demi satu. HelloBeauty selalu melakukan beberapa event berbeda sehingga peserta yang mengikuti juga tidak hanya belajar itu dan itu saja. Namun mereka bisa mengikuti acara demi acara yang diselenggarakan namun berbeda tema.

Beberapa cara yang dilakukan HelloBeauty dengan mengadakan tema berbeda diperlukan inovasi baru untuk membuat event menjadi lebih bermakna. Innovation yang artinya adalah berinovasi dengan konten kreatif, lokasi dan waktu yang tepat, dan target audiens yang tepat. HelloBeauty juga sudah mempunyai targetnya tersendiri. HelloBeauty selalu melakukan event berbeda disetiap event. Lokasi dan waktu yang tepat sesuai dengan ketersediaan makeup artistnya.

Integrity merupakan sebuah unsur event yang dilihat sebagai sesuatu yang benar dan membawa manfaat yang nyata dan nilai yang berarti untuk konsumen. HelloBeauty tentunya dalam membuat suatu event sudah memikirkan hal-hal yang akan berdampak bagi para peserta baik itu beauty artist ataupun peserta yang mengikuti acara tersebut. Tentunya HelloBeauty ingin agar setiap peserta akan mendapatakan keuntunganya masing-masing. Seperti para beauty artist tentu saja dalam hal ingin memdapatkan pemasukan atau income dari setiap event yang berlangsung dan begitu juga sebaliknya bagi para peserta tentunya ingin mendapatkan ilmu ataupun skill makeup dari para beauty artist.

Tujuan diadakannya event ini adalah untuk membuat HelloBeauty lebih dikenal, dan untuk menjalin silaturahmi antar makeup artist, dan peserta. Event ini diadakan untuk membuat komunitas makeup artist di Indonesia menjadi lebih besar dan berkembang. Tujuan lainnya adalah untuk membuat konsumen Hellobeauty tidak serta merta mengetahui HelloBeauty hanya sebatas penyedia layanan jasa beauty artist, melainkan dengan adanya acara yang diselenggarakan ini dapat membuat konsumen tertarik untuk mengikuti acara yang diadakan oleh HelloBeauty selanjutnya.

\section{Social Media Activation}

Di era globalisasi ini, beberapa media sosial menjadi sebuah alat komunikasi yang digunakan oleh masyarakat. Salah satu media sosial yang sedang banyak diminati adalah instagram. Saat penulis meminta keterangan mengapa Dennish memilih Instagram sebagai salah satu promosinya adalah karena menurut riset yang telah beliau lakukan, instagram merupakan salah satu tempat beauty artist berkumpul.

Karena beberapa alasan yang dijelaskan oleh Dennish, maka HelloBeauty melakukan social media activation dengan beberapa cara seperti membuat tips-tips makeup, membuat giveaway, live instagram saat acara offline berlangsung sehingga konsumen bisa menikmati acara walaupun mereka berhalangan hadir ke acara tersebut.

HelloBeauty juga melakukan konstes makeup di instagram bersama @ kimmaya.co. kimmaya dan HelloBeauty kontes makeup look dengan tema day and night. Dengan melakukan acara kegiatan di media sosial harapan Dennish adalah agar masyarakat lebih mengenal HelloBeauty dan untuk pemenangnya Dennish juga percaya bahwa loyalitas dihasilkan pemenang yang mengikuti acara HelloBeauty. 
Yuli Yantimas, Diah Ayu Candraningrum: Analisis Brand Activation Hellobeauty dalam Membangun Loyalitas Konsumen

\section{Loyalitas}

Kepuasan adalah perasaan senang atau kecewa seseorang karena membandingkan kinerja yang dipersepsikan produk terhadap ekspetasi mereka. Jika kinerja sesuai dengan ekspetasi, pelanggan akan puas. Jika kinerja melebihi ekspetasi, pelanggan akan sangat puas. Terutama jika hubungan loyalitas yang dimiliki pelanggan dengan sebuah merek. Ekspetasi berasal dari pengalaman pembelian masa lalu seperti nasihat teman, rekan, serta informasi dan janji pemasar ( Kotler \& Keller, 2009:134).

Terdapat empat indikator loyalitas konsumen menurut Irawan (2009) yaitu kualitas produk yang menjelaskan bahwa pelanggan akan puas jika kualitas produknya baik. Stephany menjelaskan bahwa kualitas produk seperti jasa yang disediakan dan yang ia pilih sangat memuaskan dengan harga yang sesuai dengan budgetnya.

Harga yang rendah menimbulkan persepsi kualitas rendah, sedangkan harga yang tinggi menimbulkan persepsi kualitas tinggi. Stephany menjelaskan bahwa harga yang disediakan juga bermacam-macam dan dengan harga yang sesuai dengan kantongnya, Stephany mendapat harga yang sesuai dengan makeup.

Service quality tergantung terhadap tiga hal yaitu sistem, teknologi, dan manusia. Stephany menjelaskan bahwa sistem HelloBeauty sudah sangat bagus dan mudah untuk diaplikasikan. $C E O$ Hellobeauty juga mempunyai karakter yang baik.

Emotional factor yang bergantung pada gaya hidup seseorang. Perasaan bergejolak yang menggetarkan individu sehingga hal itu tampak dari luar. HelloBeauty berhasil membuat salah satu customernya yaitu Stephany untuk menjadi salah satu pelanggan setia HelloBeauty yang disertai oleh pengakuannya. Karena kemudahan yang diberikan oleh HelloBeauty membuat Stephany beberapa kali memesan jasa melalui HelloBeauty sehingga Stephany pun dengan sukarela mempromosikan HelloBeauty kepada teman, dan keluarga.

Biaya dan kemudahan, hal ini merupakan suatu pengorbanan yang dilakukan oleh pelanggan untuk mendapatkan produk atau layanan yang relatif mudah, nyaman, dan efisien. Biaya yang ditawarkan HelloBeauty untuk peserta yang akan mengikuti acaranya tergolong murah. Dan dengan kemudahan dalam pembayaran serta pendaftaran membuat HelloBeauty semakin mudah untuk menarik pelanggan.

\section{Simpulan}

HelloBeauty merupakan e-marketplace jasa kecantikan nomor satu di Indonesia. HelloBeauty hadir untuk membantu perempuan Indonesia atau penggemar dunia kecantikan untuk mendapatkan beauty artist sesuai dengan kebutuhan dan budgetnya. HelloBeauty juga membantu beauty artist dalam mengembangkan bisnisnya untuk menjadi beauty artist yang berkompeten. Beberapa kelebihan yang dimiliki HelloBeauty adalah harga yang ditawarkan bervariasi sesuai dengan kebutuhannya. Kemudahan untuk mengakses web HelloBeauty merupakan salah satu keuntungan yang memudahkan para pengguna HelloBeauty. HelloBeauty melakukan brand activation melalui dua cara yaitu social media activation dengan instagram dan marketing event activation dengan beberapa event. Dengan melakukan brand activation, HelloBeauty dapat mencapai tujuan loyalitas konsumen. 


\section{Ucapan Terima Kasih}

Penulis sangat berterimakasih kepada keluarga, dosen pembimbing, kerabat, pacar, informan, narasumber dan teman-teman penulis yang selalu memberikan semangat ketika penulis merasa putus asa. Penulis juga selalu disemangati dan diberikan arahan yang positif saat mengerjakan penelitian ini. Hal ini tentunya membuat penulis bersemangat untuk membuat skripsi sesuai dengan waktu yang ditetapkan.

\section{Daftar Pustaka}

Emzir (2016). Metodologi Penelitian Kualitatif Analisis Data. Jakarta: PT. Raja grafindo persada.

Irawan, H. (2009). 10 Prinsip Kepuasan Pelanggan. Jakarta: Elex Media Komputindo.

Kodong, Frans Richard (2012), Model Aplikasi E-Market Sebagai Sarana Promosi Dan tukar - menukar informasi antara penjual dan pembeli. Volume 8, Nomor 2, Januari 2012.

http://jurnal.upnyk.ac.id/index.php/telematika/article/viewFile/446/414

Kotler dan Keller.(2009). Manajement Pemasaran. Jilid1. Jakarta: Erlangga.

Lexy,J.Moleong.(2008) Metodologi Penelitian Kualitatif. Bandung: PT Remaja Rosdakarya.

Lexy.J.Moleong.(2010). Metodologi Penelitian Kualitatif. Bandung: PT Remaja Rosdakarya.

Lubis, Mahdalena (2017), Pencapaian Brand Corporate melalui Brand Activation Pendekatan Experimental Marketing, Volume 9, Nomor 1, Juli 2017

https://media.neliti.com/media/publications/137668-ID-pencapaian-brand-corporatemelalui-brand.pdf

Maulana Miftah Shabur, Susilo Heru,Riyadi (2015), Implementasi e-commerce sebagai media penjualan online, Volume 29, Nomor 1, Desember 2015.

https://media.neliti.com/media/publications/86512-ID-none.pdf

Noor, Ani.(2009). Management Event. Bandung: Alfabeta

Sujarweni.v. Wiratna.(2014). Metode Penelitian : Lengkap, Praktis, dan Mudah Dipahami. Yogyakarta: pustaka baru press.

https://www.liputan6.com/bisnis/read/3905013/kadin-akui-marketplace-berikanakses-pasar-besar-buat-ukm 